\title{
LA ESTRUCTURA ACTO-OBJETO COMO ESTRUCTURA DE LA INTELECCIÓN EN SCHELER Y POLO
}

\author{
THE ACT-OBJECT STRUCTURE AS STRUCTURE OF THE \\ INTELLECTION IN SCHELER AND POLO
}

\author{
Gonzalo Alonso Bastarreche \\ Universidad de Navarra (España)
}

Recibido: 10-10-2014

Aceptado: 02-11-2014

Resumen: Tanto Scheler como Polo aceptan la estructura acto-objeto para explicar el conocimiento intelectual. Pero no la entienden del mismo modo. Scheler defiende la prioridad del objeto (el objeto se da) y Polo la del acto (la operación presenta el objeto). Para Scheler el acto es intencional y para Polo lo es el objeto. Ambos detectan que esta estructura tiene un límite, porque el acto no es nunca el objeto.

Palabras-clave: acto, objeto, operación, estructura, dualidad, intuición, inmanencia, intencionalidad, dación.

\begin{abstract}
Both Scheler and Polo use the act-object structure to explain the intelectual knowledge. Nevertheless, they don't understand this structure on the same way. Scheler holds the priority of the object (the object is given by itself) and Polo on his behalf holds the priority of the act (the operation presentates the object). For Scheler the act is intentional, but for Polo which is intentional is the object. Both observe that this structure has a limit, because the act is never the object.
\end{abstract}

Key-words: act, object, operation, structure, duality, intuition, immanence, intentionality, self-giving.

Para ambos pensadores, Max Scheler y Leonardo Polo, lo específico de la intelección, entendida ésta en sentido amplio simplemente como el conocimiento en ejercicio de la inteligencia, es precisamente su carácter de ejercicio. Dicho carácter, cuya puesta de relieve puede parecer una perogrullada o una trivialidad, ha podido verse desplazado a lo largo de la Historia de la Filosofía por ciertas concepciones del funcionamiento de la inteligencia, en mayor o menor grado pasivas. De acuerdo a Scheler y Polo, se podría decir resumidamente que conocer es ejercer el conocimiento, no asistir a su constitución exógena. 
Si el conocer es tal sólo en cuanto ejercido, esto implica inmediatamente una estructura determinada interna al conocer. Dicha estructura es una dualidad en unidad, o por mejor decir, dos dimensiones que se complementan de algún modo: lo conocido y el conocerlo; o dicho en términos más precisos, el objeto y el acto. Todo conocimiento (que no lo sea en potencia) es un ejercicio del conocimiento que conoce un algo en correspondencia con dicho ejercicio. En esto coinciden ambos pensadores también, y es el tema de este trabajo.

Esta idea es fácil perderla de vista si no se asume como tesis fundamental. La simplicidad de esta tesis la podría tornar trivial, pero es digna de atención por el rendimiento gnoseológico que tiene si se la examina profundamente.

La estructura de este breve trabajo será exponer primero las concepciones al respecto de ambos autores, para luego compararlos. No pretende ser exhaustivo, sólo incitar a la consideración del tema dando unas pinceladas.

Hay que decir que aquí nos restringimos a la inteligencia; pero ambos autores aplican la estructura acto-objeto a más dimensiones: Scheler la aplica también al percibir sentimental de los valores y al conocimiento sensible, y Polo la aplica también al conocimiento sensible y al actuar de la voluntad.

\section{La estructura acto-objeto según Scheler}

Lo deseable sería hacer, a partir de los textos schelerianos, una historia o relato de su descubrimiento de la correlación acto-objeto (AktGegenstand) como estructura fundamental del conocimiento. Pero no se puede, porque Scheler la asume sin justificar porqué. No obstante, se puede formular una hipótesis plausible. Esto es ya una tesis relevante que vamos a demostrar, y al hilo de esta demostración veremos cómo comprende Scheler dicha estructura.

Scheler asume dicha estructura como evidente, no la pone en duda. Se podría decir que es el núcleo teórico heredado de la idea de fenomenología de Husserl (y antes de Brentano). Incluso se podría decir que es asumida antes de su etapa fenomenológica, como ha puesto de relieve el profesor Alejandro Vigo ${ }^{1}$. Scheler la sostiene con firmeza incluso aunque le resultará problemática para su intento de conocer el espíritu (intento que culminaría su personalismo antropológico). Precisamente por esta firmeza y por haberla tomado como evidencia, es evidencia primera, tesis metodológica fundamental de su comprensión de la fenomenología y de su entera filosofía; es más: "se puede decir que Scheler tiene su punto de partida filosófico en su atenerse a esta experiencia, a este

[1] Cfr. Vigo, A.; "Max Scheler y la idea de una lógica trascendental de la corrección", en A. G. VIGO; Juicio, experiencia, verdad. De la lógica de la validez a la fenomenología, Eunsa, Pamplona, 2013, pp. 73-102. Desde el principio, Max Scheler critica aquellas posturas que suponen una escisión entre los actos de pensar y sus objetos.

THÉMATA. Revista de Filosofía, №50 julio-diciembre (2014) pp.: 273-293 doi: 10.12795/themata.2014.i50.13 
'hecho puro' "2. Haya dice que la distinción entre acto y objeto en Scheler no sólo es un tópico gnoseológico, sino que es distinción metafísica hegemónica ${ }^{3}$.

En Der Formalismus II, 1 se encuentra la explicación más precisa que Scheler hace de su concepción de la experiencia fenomenológica (y del a priori fenomenológico, pieza metodológica crucial de su filosofía). Por experiencia fenomenológica (también llamada intuición pura o fenomenológica) Scheler entiende intuición intelectual ${ }^{4}$. En la descripción de la experiencia fenomenológica se ve claramente cómo Scheler discurre habiendo asumido previamente la estructura acto-objeto, desde el primer párrafo:

"Designamos como "a priori" todas aquellas unidades significativas ideales y proposiciones que, prescindiendo de toda clase de posición de los sujetos que las piensan y de su real configuración natural, y prescindiendo de toda índole de posición de un objeto sobre el que sean aplicables, llegan a ser dadas por sí mismas (zur Selbstgegebenheit kommen) en el contenido de una intuición inmediata (unmittelbare Anschauung). (...) Al contenido de una intuición de tal índole lo llamamos un fenómeno." ${ }_{5}$

La distinción entre contenido e intuición es paralela a la de acto y objeto; y en este fragmento Scheler la ha asumido estructuralmente: está hablando de un tipo especial de acto con un tipo especial de objeto, dando por hecho dicha distinción. ¿Tenía acaso alguna alternativa? Sí, pudiera ser: la distinción sujeto-objeto, que es sustancialmente distinta de la de acto-objeto, pero empleada también como inicio del abordaje del conocimiento. Scheler, puesto que distingue métodos de conocimiento (clases de actos) posiblemente haya decidido no emplear una dualidad

[2] Santamaría, M.G.; Acción, persona, libertad. Max Scheler-Tomás de Aquino, Eunsa, Pamplona 2002, p. 34.

[3] Haya Segovia, F.; Tiempo y método en Max Scheler, Cuadernos de Anuario Filosófico, Serie Universitaria, Servicio de Publicaciones de la Universidad de Navarra, Pamplona, 2011, p. 25.

[4] Cfr. Der Formalismus, GW 2, 51996, p. 67-99. A grandes rasgos, intuición intelectual para Scheler significa lo siguiente: según Kant (único interlocutor de Scheler junto con Husserl en esta argumentación) toda intuición (en el sentido de contacto directo, no mediato con lo real) es a posteriori y propiedad del conocimiento sensible; y eso a Scheler le parece una devaluación del conocimiento intelectual, el cual queda relegado a formar (dar forma) al caos de sensaciones en que es intuido lo real. De este modo, no habría a priori material (pues todo lo material se reduce a sensible a posteriori y lo a priori o intelectual es meramente formal), y esto impediría a Scheler fundamentar una materiale Wertethik, ya que una ética racional quedaría relegada a formale imperative Ethik. Empleo la expresión "lo real" en su sentido más intuitivo y menos comprometedor metafísicamente. Tengo en cuenta que comparo dos pensadores que consideran, respectivamente, "el ser" y "lo real" como una mera posición (cfr. Kant, I.; KrV, A598 B626; Scheler, M., Der Formalismus, GW 2, p. 67-8), pero esto es cuando se entiende "lo real” como una categoría metafísica concreta. De todos modos, el término puede ser intercambiado por otros cualesquiera, siempre que refieran solamente a "lo extramental" en sentido amplio.

[5] Der Formalismus, GW 2, p. 67-8. La intención original del texto es diferenciar la intuición de todo tipo de conocimiento simbólico, tema que trataremos a lo largo del trabajo; pero aquí lo citamos sólo como ejemplo de lo dicho.

THÉMATA. Revista de Filosofía, №50 julio-diciembre (2014) pp.: 273-293

doi: 10.12795/themata.2014.i50.13 
que le obligue a reducirlos todos a la noción de sujeto. He aquí la hipótesis acerca del origen de la dualidad en Scheler ${ }^{6}$.

Scheler continúa esta exposición del a priori fenomenológico, con la dualidad acto-objeto como semioculto telón de fondo varias páginas, hasta que la saca a relucir en el momento en que le sirve para criticar lo que él llama el "trascendentalismo kantiano del a priori". Este trascendentalismo consistiría en reducir las leyes de los objetos a las leyes de los actos en los cuales son dados. En este momento, dado que ha de sacar a colación la correspondencia entre objeto y acto, hace explícita dicha correspondencia:

"La Fenomenología debe distinguir en todos los dominios sometidos a su investigación tres clases de conexiones de esencias. Primero: Las esencias (y sus conexiones de esencias) de las cualidades dadas en los actos, y cualesquiera contenidos de cosas (Fenomenología de las cosas); Segundo: Las esencias de los actos mismos y las conexiones que existen entre ellos, juntamente con sus fundamentaciones (Fenomenología de los actos o del origen); y Tercero: Las conexiones esenciales que existen entre las esencias de los actos y las esencias de las cosas"

Aquí distingue acto y objeto, e indica en qué órdenes hay que considerar ambos para no confundirlos: primero el orden de los objetos entre sí, segundo el orden de los actos entre sí, y tercero el orden de los objetos para con los actos. Acerca de este último orden dice a continuación lo siguiente: "Los actos mismos no pueden seguramente convertirse en objetos nunca ni en modo alguno, pues su ser consiste exclusivamente en la ejecución". La conclusión que Scheler saca de esto, que aquí nos interesa sólo derivadamente, es que el "trascendentalismo kantiano del a priori” es falso, porque éste implica dar preponderancia al acto sobre el objeto, y en última instancia reducir la validez del objeto a validez de las leyes de aparición del acto ${ }^{9}$. La prueba clara y concreta de que

[6] Está abierto un debate sobre si es más autoevidente, y por tanto más legítima para incoar el tratamiento del conocimiento, la dualidad sujeto-objeto o la dualidad acto-objeto. Scheler (o más bien su maestro en este sentido, Husserl; según lo que decíamos antes) opta por la segunda probablemente porque considera evidente que el sujeto realiza operaciones de conocer diversas e irreductibles entre sí (ver y oír, por ejemplo), las cuales tienen sus propios objetos, que son a su vez inintercambiables. Scheler dice esto así: "los valores están dados únicamente en el Fühlen, los colores, exclusivamente en el acto de ver, los sonidos en la audición, etc." Der Formalismus, GW 2, p. 90).

[7] Der Formalismus, GW 2, p. 90.

[8] Der Formalismus, GW 2, p. 90.

[9] Si se aceptase esto se caería, según Scheler, en un regressus ad infinitum consistente en que todo objeto es válido si son válidas las condiciones en las que ha aparecido el acto correspondiente. Pero un acto es válido según sus relaciones de fundamentación con el resto de actos y con el entendimiento, y si éste fuera el criterio de validez del conocimiento, nunca sería lo real extramental lo que otorga validez al conocimiento. Lo que otorgaría validez al conocimiento sería su dependencia en última instancia de un Entendimiento que prescribe a la Naturaleza sus leyes. Sin embargo, para Scheler, el entendimiento no prescribe nada que no sean signos convencionales (cfr. Der Formalismus, GW 2, pp. 91). Aquí, contrariamente a lo que puede parecer a primera

THÉMATA. Revista de Filosofía, N50 julio-diciembre (2014) pp.: 273-293 doi: 10.12795/themata.2014.i50.13 
esto no es cierto es que acto y objeto son irreductibles, pues un acto no puede ser nunca objeto. Es por esta razón por la que Scheler utiliza la dualidad como estructura medular del conocimiento, aunque asigne mayor preponderancia a uno u otro extremo según el tipo de conocimiento: uno es irreductible al otro, luego siempre están juntos.

En este punto hemos de dejar la exposición acerca del origen de la dualidad en Scheler y pasar a estudiar los rasgos internos de dicha dualidad. En la tesis mencionada comparecen los que quizá sean dos rasgos fundamentales de la comprensión scheleriana de la estructura acto-objeto. Estos rasgos son: por un lado, acto y objeto son irreductibles entre sí, hasta el punto de que el acto no puede ser nunca objeto; y por otro lado, el objeto parece tener cierta preponderancia sobre el acto.

Con respecto a lo primero, no hace falta decir nada, solamente que Scheler se lo toma radicalmente en serio, hasta el punto de dejar tan "atrás" el acto, que más "atrás" todavía se queda, en su antropología, la persona como origen de actos. Esto dificultará hallar el modo de conocimiento que quepa tener de la persona (en el sentido en que la entiende Scheler: como núcleo espiritual íntimo del hombre y origen irreductible de sus actos).

Con respecto a lo segundo, hay que decir que Scheler entiende la relación acto-objeto como una dación del segundo al primero. Es decir, hay verdadero conocimiento en tanto el acto no ha "generado" el objeto sino en cuanto éste le ha sido "dado". Ahora bien, dado no quiere decir dado casual o caprichosamente (dado sin competencia ninguna al respecto del acto), pues es dado a un único tipo de acto, no podría ser dado a ningún otro tipo de acto. Scheler habla no sólo de dación, sino de autodación (Selbstgegebenheit) del objeto porque hablamos del acto fundamental, la intuición fenomenológica, en la que ha de comparecer la realidad por sí misma puesto que estamos en el nivel primigenio de conocimiento. Si en este tipo de intuición el objeto ${ }^{10}$ no fuese dado por sí mismo entonces se caería en el trascendentalismo kantiano de imponer como determinantes las leyes del acto (y se caería también en lo que Scheler llama subjetivismo ${ }^{11}$ ). Digamos resumidamente que, en Scheler, la intuición fenomenológica, en cuanto acto, es el escenario idóneo para la comparecencia del objeto.

Es precisa una aclaración. La intuición fenomenológica no es sólo intuición intelectual o sólo intuición sensible, puede referir a cualquiera de ambos

vista, Scheler no intenta evadir el subjetivismo, sino el trascendentalismo. El subjetivismo, del que también acusa a Kant, lo criticará en otras argumentaciones (Der Formalismus, GW 2, pp. 92-6).

[10] Scheler a veces prefiere emplear el término "el hecho fenomenológico" o simplemente el fenómeno. Cfr. Lehre von den drei Tatsachen, GW 10, ${ }^{2} 1957$, pp. 431-500.

[11] El subjetivismo vendría como fatal consecuencia del trascendentalismo, pues al haber hecho depender la validez de los objetos de la validez de los actos, éstos han de depender a su vez de un yo, de un sujeto o de un "yo trascendental" o "conciencia en general". De este subjetivismo, Scheler sólo se atreve a acusar a Kant con reservas (cfr. Der Formalismus, GW 2, pp. 92-6.

THÉMATA. Revista de Filosofía, №50 julio-diciembre (2014) pp.: 273-293

doi: 10.12795/themata.2014.i50.13 
niveles, porque es una noción elaborada en función de otro criterio, el de la inmediatez (o autodación) del objeto ${ }^{12}$. Ahora bien, Scheler expone principalmente la posibilidad de la intuición fenomenológica a nivel intelectual porque, como ya hemos dicho, su contrincante aquí es Kant con su teoría de que la intuición sólo es sensible.

Para entender adecuadamente la prioridad del objeto sobre el acto en Scheler, hay que escarbar dicha estructura en las dos formas de conocimiento que Scheler considera distintas e inferiores ${ }^{13}$ a la intuición fenomenológica: la concepción natural del mundo (natürliche Weltanschauung) y la concepción científica del mundo (wissenschaftliche Weltanschauung). En éstas la preponderancia del objeto no es tan palmaria, o más bien hay que exponerla de otro modo. Esto nos ayudará a precisar el modo en que la entiende Scheler. Veámoslo en un texto concreto que vale la pena citar entero porque, a pesar de su extensión, es extremadamente corto sintético si se tiene en cuenta la radicalidad de la cuestión:

"Los dos tipos de hechos de que aquí se trata (el hecho de la concepción natural del mundo y el hecho de la ciencia) tienen en común (...) que un hecho tal nunca es traído, por principio, en un acto de conocimiento. Más bien, es característico de ambos hechos que el acto que los capta (sea éste de naturaleza intuitiva o conceptual) se refiera, según su intención, a un plus respecto a lo que se da en el contenido del acto en su realización. A este referirse a más y a algo además de lo fenomenológicamente inmanente lo llamamos trascendencia (Transzendenz) del acto. En esta medida, ambos tipos de hechos también pueden ser llamados hechos trascendentes.

(...) A la trascendencia de estos hechos se añade un segundo rasgo común: nunca están presentes en sí mismos (selbst gegenwärtig) ni dados en sí mismos (selbst gegeben), sino que lo dado en ellos (...) es, o bien sólo signo y símbolo de ellos, o bien contenidos que están como signos o símbolos de ellos, no desapareciendo de este modo totalmente. Se dan, entonces, siempre y necesariamente de modo mediato, y nunca inmediatamente.

(...) Mediatamente dado se debe denominar aquí todo lo que no está en el contenido fenomenológico.

(...) Al segundo rasgo común de ambos tipos de hechos, aquí expuesto, queremos llamarlo el simbolismo (Symbolismus) de la experiencia natural y científica; y al común estar determinado de ambos hechos, la mediación de su ser dado"14

[12] "La diferencia, aquí determinada, entre autodación y dación simbólica de un objeto no tiene absolutamente nada que ver, pero ni lo más mínimo, con la oposición entre contenido sensible y contenido no-sensible" Lehre von den drei Tatsachen, GW 10, pp. 458.

[13] Empleo estos dos adjetivos porque se deducen claramente de la exposición scheleriana. Que además ambas formas de conocimiento sean complementarias con la intuición fenomenológica, sería una tesis que habría que demostrar, porque como se verá Scheler parece minusvalorarlas, describiéndolas como imperfectas frente a la intuición fenomenológica, como veremos en la comparación entre los autores.

[14] Lehre von den drei Tatsachen, GW 10, pp. 456-8.

THÉMATA. Revista de Filosofía, Nº50 julio-diciembre (2014) pp.: 273-293

doi: 10.12795/themata.2014.i50.13 
Scheler ha expuesto aquí lo que llama trascendencia y simbolismo del objeto del acto de la concepción natural y del acto de la concepción científica. Ambas están muy interrelacionadas, como puede verse en el texto. Lo que quieren decir es que el objeto no se da exclusivamente en sí mismo, sino que comparece junto con más aspectos (trascendencia) y que comparece a través de un símbolo suyo (simbolismo). Como reza la conclusión del texto, hablamos de una mediación en el darse del objeto. Según lo que hemos visto, estas dos características se oponen a las de la intuición fenomenológica, que son precisamente la inmanencia y la autodación (o asimbolismo).

Lo relevante aquí para nuestra investigación es que ambas características suponen una prevalencia del acto frente al objeto. Ésta es clara en el momento en que Scheler ha dicho que el entendimiento sólo puede prescribir a la Naturaleza signos convencionales ${ }^{15}$; de modo que, donde haya signos convencionales (como es en el caso que nos ocupa), habrá una prescripción por parte del entendimiento, que de este modo "sobresale". Scheler lo dice también de otro modo: en toda experiencia trascendente o no fenomenológica "es mentado o supuesto (vermeint) algo que no es dado intuitivamente en ella"16. Es decir, el acto en cuestión pone algo de su parte y menta algo que no le es dado en el objeto mismo. Esto ocurre en el conocimiento de un hecho no fenomenológico. En el hecho fenomenológico, por el contrario, dice Scheler que coinciden lo pensado (Gemeinte) y lo dado. Esto tiene una dificultad, y es que la intervención del acto supone un ligero ocultamiento del objeto, que es diluido mediante símbolos ${ }^{17}$. Allá donde el acto prescribe sus leyes, el objeto queda desdibujado, entenebrecido; además de desbordado. Por el contrario, la experiencia fenomenológica según Scheler, en frase plástica, permite que el objeto se cumpla, en tanto en ella coinciden lo pensado y lo dado ${ }^{18}$, en tanto el acto se reduce a mostrar el objeto.

En esta línea, es consecuente que Scheler diga que el acto de conocer es intencional. Tanto el de la intuición fenomenológica, como el de la concepción natural como el de la ciencia. Lo que entiende por intencionalidad del acto se comprende adecuadamente acudiendo a la clasificación que hace de los estra-

[15] Cfr. Der Formalismus, GW 2, pp. 91.

[16] Lehre von den drei Tatsachen, GW 10, pp. 433. Esta frase no es de Scheler exactamente, sino un resumen de sus ideas insertado aquí por la editora de las Gesammelte Werke. De todos modos refleja fielmente su pensamiento, pues es resumen de las ideas schelerianas expuestas en Der Formalismus.

[17] Por esta razón todo hecho debe estar precedido de un hecho fenomenológico para llamarse legítimamente conocimiento: "la fenomenología se sostiene o cae con la afirmación de que haya tales hechos, de que ellos sean propiamente los que estén en la base de todos los demás hechos (los hechos de la concepción natural del mundo y de la concepción científica del mundo) y de que sus conexiones estén en la base de todas las demás conexiones" Lehere von den drei Tatsachen, GW 10, p. 448.

[18] "En la coincidencia de lo pensado y lo dado aparece (erscheint) el «fenómeno», se cumple (erfüllt sich) el contenido de la experiencia fenomenológica" Lehre von den drei Tatsachen, GW 10, pp. 433.

THÉMATA. Revista de Filosofía, №50 julio-diciembre (2014) pp.: 273-293 doi: 10.12795/themata.2014.i50.13 
tos de la vida emocional ${ }^{19}$. Aunque habla de actos sentimentales, no cognoscitivos, la intencionalidad como nota del acto queda igualmente aclarada; porque ésta es una característica neutral, es decir, independiente de la clase de acto, que sólo revela el tipo de relación de cada acto a su objeto. La clasificación es interesante porque revela la intencionalidad por contraposición entre los estratos sentimentales que la poseen (sentimientos espirituales, anímicos y vitales) y los que no (sentimientos sensibles).

Intencionalidad quiere decir según Scheler, a fin de cuentas, que el acto tiene objeto concreto. Aquí Scheler hace uso de una distinción lingüística que en castellano no es posible: contrapone Objekt y Gegenstand. Al castellano se vierten indistintamente como objeto. Todo acto tiene Objekt en tanto tiene una causa o alguna realidad que lo ha provocado, incluidos los sentimientos sensibles: por ello, el Objekt está "tras" el acto. El Gegenstand, por el contrario (haciendo uso precisamente de la etimología de la palabra) está "frente" al acto, es el contenido concreto del acto ${ }^{20}$. Así las cosas, la relación del acto a su Gegenstand es intencional, el acto refiere a su Gegenstand. Al referir a él, lo presenta (y entonces hay conocimiento legítimo). Esto sólo se puede sostener si se considera que el Gegenstand es real, no intencional, es la misma realidad en cuanto tal la que comparece en el acto.

Así se puede decir que entiende Scheler, a grandes rasgos, la dualidad acto-objeto como estructura medular del conocimiento.

\section{La estructura acto-objeto según Polo}

En el caso de Polo es posible hacer un relato de su asunción de la estructura acto-objeto, porque declara haberla encontrado en Aristóteles y Tomás de Aquino $^{21}$. No es necesario hacer exhaustivamente dicho relato, basta con mostrar que el punto de partida es distinto con respecto a Scheler, puesto que Polo entronca directamente con la tradición gnoseológica clásica.

Antes de empezar, es precisa una aclaración terminológica: Polo no habla de acto-objeto sino de operación-objeto, reservando el término acto para hablar, en primer lugar, de la unidad de operación y objeto en estricta inmanencia. El término operación es herencia tomista. Además, puesto que, siguiendo la tradición clásica, considera que hay más conocimiento intelectual que el operativo-objetivo, amplia el término acto para decir que también el conocimiento transobjetivo (los hábitos y el intelecto agente) son conocimiento en acto. Veremos qué significa esto.

[19] Der Formalismus, GW 2, pp. 331-346.

[20] Como resulta evidente, cuando en este trabajo hablamos de objeto nos referimos al Gegenstand.

[21] Cfr. Curso de Teoría del Conocimiento, Tomo I, Eunsa, Pamplona ${ }^{32006, ~ p p . ~ 39-73 ~(e n ~}$ adelante Curso, Tomo "x"); González Ginocchio, D.; El acto de conocer. Antecedentes aristotélicos de Leonardo Polo, Cuadernos de Anuario Filosófico, Serie Universitaria, Servicio de Publicaciones de la Universidad de Navarra, Pamplona 2005.

THÉMATA. Revista de Filosofía, №50 julio-diciembre (2014) pp.: 273-293

doi: 10.12795/themata.2014.i50.13 
Retomando el debate mencionado sobre la conveniencia o inconveniencia de traer al sujeto a colación en la teoría del conocimiento, ésta es la tajante postura poliana:

"La inclusión del sujeto cognoscente en la teoría del conocimiento humano es perturbadora. La razón de ello es fundamentalmente la siguiente: al sujeto humano se le hace intervenir como factor constituyente. Ahora bien, la tesis según la cual la subjetividad es constitutiva del conocer humano es rotundamente falsa y acarrea un grave inconveniente para establecer la noción de operación. El conocimiento es operativo, y eso quiere decir que tiene un carácter suficiente en cuanto que se ejerce. Si al sujeto lo consideramos como constitutivo del conocer, el carácter operativo del conocer se pierde."

Para Polo, que "el conocimiento es acto" es un axioma de su gnoseología, en concreto el axioma primero. Es decir, es una proposición necesariamente verdadera cuyo contrario es falso, y que por lo tanto tiene la dignidad suficiente para fundar en base a él la teoría del conocimiento. Se opone al postulado, que admite un contrario verdadero, y sin embargo se le otorga la misma dignidad por otros motivos (por convención o por simple rendimiento). Toda la teoría del conocimiento de Polo se deriva de este axioma, de la cual se derivan a su vez otros axiomas de diversa dignidad ${ }^{22}$.

Exponer la opinión de Polo respecto de la estructura operación-objeto es sencillo, pues se reduce a tres tesis axiomáticas. Lo difícil es que esas tesis se entiendan en toda su hondura, o al menos en lo que tienen de similar y opuesto con las tesis schelerianas. Para lograr esto, prefiero empezar exponiendo dos puntos de partida de Polo que son diametralmente distintos a los de Scheler. De este modo se encuadrará más rápidamente la postura poliana, y quedará abierta su compatibilidad con la scheleriana.

\subsection{Punto de partida de Polo}

El punto de partida de Polo, en lo que tiene de opuesto a Scheler, se puede resumir en dos sencillas tesis que fueron formuladas por los escolásticos.

La primera de estas tesis es que para las cosas, ser conocidas es una denominación extrínseca $a^{23}$. Las cosas no son conocidas en sí mismas, son cognoscibles en potencia y ser efectivamente conocidas les adviene posterior y extrínsecamente. Las cosas no son en sí mismas objeto de ningún conocimiento, son objetos reales y sólo secundariamente se convierten en objeto de un entendimiento. Secundariamente,

[22] Cfr. Curso Tomo I, pp.21-36.

[23] Cfr. J. de Santo Tomás; Verdad trascendental y verdad formal, a. I, nn. 43-45, Eunsa, Pamplona 2002, pp. 188-190. Para Polo, puesto que es fundamental, es una tesis traída a colación con frecuencia, al menos en Curso Tomo I, p. 121, 122, 130, 164, 263, 272; Tomo II, Eunsa, Pamplona ${ }^{4} 2006$, p. 66, 69, 136, 147, ; Tomo IV/1, Eunsa, Pamplona 1994, p. 61, 62, 91; Persona y libertad, Eunsa, Pamplona 2007, p.54, 96, 134, 135, Nietzsche como pensador de dualidades, Eunsa, Pamplona 2005, p. 220; Antropología trascendental, Tomo I, Eunsa, Pamplona ${ }^{3} 2010$, p. 69.

THÉMATA. Revista de Filosofía, №50 julio-diciembre (2014) pp.: 273-293 doi: 10.12795/themata.2014.i50.13 
es un término importante aquí, porque tiene valor metafísico. Puesto que es un término metafísico, no quiere decir "en un segundo momento", sino que refiere a que esencialmente es accidental a la cosa real ser conocida, y cuando es conocida no lo es directamente, sino según una forma o semejanza (como veremos más adelante). No hay por tanto una operación en la que lo real sea dado en su total realidad o esencia, por contraste a otras operaciones en que lo real sería dado entenebrecidamente ${ }^{24}$. La distinción entre operaciones se establece en base a otro criterio (el tipo de objeto que tiene), pero lo real es "dado" cognoscitivamente siempre de modo secundario a como existe extramentalmente (al modo de la semejanza de su forma, dirían los escolásticos siguiendo a Aristóteles; veremos esto en la segunda tesis).

Esta tesis se puede decir de varias maneras, remarcando aspectos distintos: "la verdad está en sentido estricto en la mente"25, o "el ser de la cosa, no su verdad, causa la verdad en el intelecto" 26 . Si lo conocido no es directamente lo real, entonces la verdad, como "objeto" propio del conocimiento, está más bien en el conocimiento que en las cosas. Esto no quiere decir que la verdad sea subjetiva, sino que la verdad no añade nada a lo real en cuanto real ${ }^{27}$. La verdad en lo real no está propiamente, pues que estuviera no añadiría nada, sería una perogrullada: sólo añade algo si se predica de un entendimiento que podría faltar a esa verdad. Aquí viene al caso emplear los consagrados términos de acto y potencia: la realidad es cognoscible en potencia, no conocida en acto (en cuanto real): en cuanto real, lo que la cosa tiene de cognoscible es potencial. "La cosa extra mentem es real, pero no es, de suyo, actualmente conocida. Esta tesis es profundamente aristotélica y todavía más profundamente tomista"28. Ahora bien: la causa, o el motivo de la verdad en

[24] Esto no tiene que ver con la distinción, dentro de la inteligencia, entre las operaciones conceptuales y las judicativas, que refiere a otra cuestión y que sigue vigente.

[25] Tomás de Aquino; De Veritate, q. 1, a. 2, ad1; a. 4, adc 1; S. Th I, q. 16, a. 1, co. Esta tesis se remonta a su vez a Aristóteles; Metafísica VI, 4, 1027b25-30.

[26] "Esse rei, non veritas eius, causat veritatem intellectus" Tomás de Aquino; S. Th. I, q. 16, a. 1, ad 3; POLO; Curso, Tomo I, p. 120. Sobre la relación entre la primera formulación y ésta, dice Polo que: "la tesis según la cual ser conocido es una denominación extrínseca para la cosa está en correlación con esta obra: "el ser de la cosa, no su verdad, causa la verdad". La cosa no es inteligible en acto, sino en potencia" (íbid., p. 122).

[27] "Verum nihil addit reale supra ens: nihil enim plus significatur per hominem verum quam per hominem, per albedinem verum quam per albedinem", Cayetano; In S.Th., 1, 1, V, Ed. Leonina, vol VIII, p. 8. Esta tesis, para hacer justicia al pensamiento escolástico, hay que predicarla de la verdad formal, es decir, la verdad respecto del entendimiento humano; no de la verdad ontológica o trascendental, es decir, la verdad en el entendimiento divino; la cual se podría decir que sí está en las cosas. "Se puede ser sin ser conocido por mí, pero ¿ser sin ser conocer o conocido, en absoluto? Aquí nos lo jugamos filosóficamente todo. Hay que decidir si cabe ser al margen del conocer en absoluto. La respuesta es inmediata: no cabe en modo alguno. Cualquier vacilación al respecto es materialismo" (Curso, Tomo I, p. 51-2).

[28] Curso, Tomo I, p. 46. La idea la expresa Aristóteles así: "lo que está en el alma no es la piedra, sino la forma de esta" De Anima III, 8 (432 a 1)

THÉMATA. Revista de Filosofía, Nº50 julio-diciembre (2014) pp.: 273-293

doi: 10.12795/themata.2014.i50.13 
el intelecto, no es tarea del intelecto mismo sino de la cosa en cuanto real. Si fuese tarea del intelecto mismo, sí que caeríamos en un puro subjetivismo (o quizás en un formalismo). La verdad la encuentra el intelecto en tanto es capaz de descubrir la correspondencia de su objeto con la realidad. Dicho de modo más sencillo y en contraste con el idealismo moderno, esse non est percipi.

La segunda tesis está directamente vinculada a la anterior, es consecuencia de tomarse la tesis anterior ontológicamente en serio. Dice así: "lo recibido es recibido al modo del recipiente" ${ }^{29}$. Esta tesis clásica implica que cuando la operación tiene lo conocido, lo tiene según el modo de la operación y no según el modo de lo real. De modo que entre el objeto de la operación y la cosa real hay siempre un entre. La cosa no es tenida en sí misma, sino según una semejanza formal (la expresión es claramente de inspiración aristotélica, nos parece la más adecuada). Esto es consecuencia de sostener que la cosa en cuanto tal no es conocida en acto: cuando pasa a ser conocida en acto, no es ella misma sino que ella no pasa de ser causa de su conocimiento.

Esta segunda tesis, se puede decir así, precisando un poco más cuál es la índole de ese "modo del cognoscente": "nuestro intelecto conoce trayendo a sí y considerando dentro de sí, no inspeccionando fuera" ${ }^{30}$. Comentando Polo, dice: "el entendimiento entiende de modo inmanente. No hay inspección de algo externo, sino posesión"31 (¿posesión de qué? Del objeto, como veremos). Reforzando lo ya dicho antes, no hay una operación que traiga a presencia la cosa en sí misma, sino que toda operación conoce trayendo a sí a su modo, al modo de lo intelectual (esto era claro para Aristóteles y los escolásticos en virtud de que la inteligencia no poseía la materialidad de las cosas que conocía).

\subsection{La estructura acto-objeto según Polo}

Como decíamos, la postura de Polo respecto de la estructura operación-objeto es resumible en 3 sencillas tesis, que corresponden a tres axiomas. $\mathrm{Al}$ decir de Polo, se trata de un axioma central y dos laterales (lateral significa que son desarrollos del axioma central respectivo) Ahora cabe exponerlas con menos riesgo de no ser entendidas:

[29] Tomás de Aquino; S. Th I, q. 75, a. 5, co, etc. No se refiere al modo del sujeto cognoscente, sino al modo de la facultad que conoce (la visión, la imaginación, la inteligencia, etc.). Polo lo cita al menos en Curso, Tomo I, 194; Lecciones de psicología clásica, Eunsa, Pamplona 2008, p. 120, Hegel y el posthegelianismo, Eunsa, Pamplona ${ }^{2} 1999$ p. 47.

[30] "Intellectus ipse non intelligit nisi trahendo res ad se et intra se considerando, non extra se inspiciendo" Juan de Santo Tomás; Cursus Theologicus, q. 27, d. 32, a. 5, 11. Polo lo cita en Curso, Tomo I, p. 76, 135, 137, 223, 320, Tomo II, p. 97, 228.

[31] Curso, Tomo I, p. 76.

THÉMATA. Revista de Filosofía, №50 julio-diciembre (2014) pp.: 273-293 doi: 10.12795/themata.2014.i50.13 
1. Axioma central A: el conocimiento es acto, al menos como operación inmanente ${ }^{32}$.

2. Axioma lateral E: operación es operación de objeto, no hay objeto sin operación. A la perfecta conmensuración entre operación y objeto cabe llamarla inmanencia ${ }^{33}$.

3. Axioma lateral F: el objeto es constitutivamente intencional ${ }^{34}$.

El Axioma A significa principalmente que el conocimiento es ejercicio, no cabe hablar de que sea pasivo ${ }^{35}$. En el nivel de la operación, este axioma significa que el conocer y lo conocido son uno en acto, en estricta correspondencia. La postura contraria paradigmática es el intuicionismo, que sostiene que lo intuido se da desde sí, y conocer sería asistir a esa constitución, contemplarla. Para Polo no cabe, por tanto, hablar de dación del objeto, sino posesión del objeto. Así habla Polo de la intuición:

\footnotetext{
"Si por intuición se entiende el conocimiento inmediato, no discursivo, como el de un color, es decir, de algo cuyo aparecer no exige mediación (una inducción o una deducción o, en general, un proceso comparativo), puede decirse que, cuando vemos, cuando tocamos, o cuando concebimos, intuimos. Este sentido de la intuición es correcto. Pero si por intuición se entiende que la actividad y el protagonismo del conocimiento corre a cargo de lo conocido, hay que excluirlo: sin acto de conocer no se conoce nada y eso quiere decir que no hay nada conocido" 36 .
}

Ambos sentidos de la intuición son por tanto incompatibles. Una cosa es que no haya mediación (mediación argumentativa o comparativa, se entiende), que sería un sentido positivo de la intuición (en tanto a fin de cuentas se convierte en un término intercambiable por el de simultaneidad) y otra cosa es que el acto sea un mero escenario de un darse del objeto. En este segundo caso diríamos que es la realidad extramental como tal la que ha caído dentro del acto, pero eso no es aceptable para Polo ya que "nuestro intelecto conoce trayendo a sí y considerando dentro de sí, no inspeccionando fuera". Polo advierte de todos modos que la operación es excesivamente humilde, es decir, se limita a presentar el objeto y no a sí misma, con lo cual acecha permanentemente la tentación de atribuir toda la primacía al objeto.

[32] Cfr. Curso, Tomo I, p. 39.

[33] Cfr. Curso, Tomo I, p. 41.

[34] Cfr. Curso, Tomo I, p. 41.

[35] Ante todo o en primer lugar, este ejercicio comparece como operativo-objetivo (además éste es el aspecto más tratado por la literatura filosófica) pero para Polo no es necesario que sea sólo éste. También cabe hablar de conocimiento en ejercicio cuando se habla del conocimiento transoperativo (los hábitos intelectuales adquiridos e innatos y el intelecto agente), que tiene su propio tema. Éste es otro tema, pero hay que apuntarlo para hacer justicia a una pieza fundamental del pensamiento del autor.

[36] Curso, Tomo I, p. 53.

THÉMATA. Revista de Filosofía, Nº50 julio-diciembre (2014) pp.: 273-293 doi: 10.12795/themata.2014.i50.13 
Según Polo en continuidad con Aristóteles, la operación de conocer ha de ser llamada operación inmanente. Inmanente no se contrapone como solipsista frente a trascendente, sino como perfecto frente a transeúnte o procesual:

"El conocimiento en el caso del hombre es acto como operación. Aristóteles lo llama enérgeia y a veces también praxis; praxis en cuanto contrapuesta a kínesis, o praxis akinética. El conocimiento comparado, por ejemplo, con el correr, es inmóvil y por ello más acto; es enérgeia. (...) Enérgeia, esto es, operación inmanente. Hay que aclarar por qué se dice "inmanente". Inmanencia significa perfección; estrictamente, es la perfección peculiar, la suficiencia, del acto de conocer si ese acto es una operación" ${ }^{37}$

"Aristóteles la expresa así: cuando se edifica no se tiene lo edificado (no existe lo edificado); cuando existe lo edificado, no se edifica; y esto es praxis como medio o kinesis. En cambio, cuando se ve se tiene lo visto y se sigue viendo. (...) En rigor, el edificar no tiene nunca lo edificado puesto que al edificar no existe lo edificado y cuando existe lo edificado no se edifica. En ningún momento el edificar posee. Se tiene lo visto; se posee lo visto. Lo inmanente de la operación es la posesión. Conocer en acto, si el acto es una operación, es poseer lo conocido. Hay que añadir algo más: es tener lo conocido ya, o en pretérito perfecto."38

Según Polo hay dos tipos de movimiento, transitivo y no transitivo, y la operación inmanente es el movimiento no transitivo. Por ser no transitiva, puede hablarse estrictamente de posesión, porque su objeto comparece durante su realización, no tras ella. ¿Y qué es lo que posee la operación? El objeto, que no es la cosa extramental exactamente (como se deduce según lo dicho acerca de los presupuestos polianos y como veremos).

Operación es operación inmanente y es posesión de objeto. Aquí entra el axioma lateral E implica que no se puede "conocer nada", es decir, operación ejercida es operación con objeto, exitosa si se quiere decir así (aunque puede fracasar en tanto cabe error, pero no fracasar en tanto cabe posesión de nada). Polo formula el axioma en sentido inverso para reforzar lo dicho sobre que no cabe dación del objeto sin operación que lo posea. Una vez explicada la inmanencia deja de tener sentido (induce a equívoco) hablar de posesión del objeto, y por ello Polo pasa a hablar de presentación del objeto: la operación presenta su objeto.

Podría verse aquí un residuo de idealismo si se entendiera esto en el sentido spinoziano de "ordo et conexio idearum idem est ac ordo et conexio rerum" 39 . Pero Polo no considera que el objeto sea la cosa real extramental en sí misma, sino que dice que es intencional. Aquí entramos en el axioma $\mathrm{F}$ de los indicados antes.

[37] Curso, Tomo I, p. 53.

[38] Curso, Tomo I, p. 57.

[39] Spinoza, B.; Ética, II, prop. 7. SI Polo defendiese esto, violaría de modo craso el principio citado de que esse non est percipi.

THÉMATA. Revista de Filosofía, №50 julio-diciembre (2014) pp.: 273-293

doi: 10.12795/themata.2014.i50.13 
Respecto del axioma F, como dice el mismo Polo "la formulación del axioma $\mathrm{F}$ es fácil, pero exponer qué significa intencionalidad no lo es" ${ }^{40}$. En primer lugar, hay que decir que para Polo la intencionalidad no es una característica del acto, sino del objeto. Esto quiere decir, como hemos dicho, que el acto es posesivo, no tendente o referente: posee su objeto en estricta inmanencia, o en estricta conmensuración con él. Para Polo, hablar de acto intencional es confundir el pensar con el desear, y es en el fondo el residuo más sutil de "transitivización" de la operación de conocer, porque significa que el acto no posee su objeto conmensurándose con él. En este punto Polo es diametralmente opuesto a Scheler, y es preciso entenderlo bien. No sólo se trata de un disputare de nominibus: si se quiere decir que intencional significa que el acto tiene "un objeto concreto frente a sí y no tras de sí", pues la palabra es adecuada, pero por su habitual empleo filosófico encierra un residuo de distancia entre las realidades que vincula. Esa distancia para Polo implica romper la fuerte unidad en que se encuentran acto y objeto, por eso emplea los términos de posesión o conmensuración ${ }^{41}$. Dicho rápidamente: el acto no menta o refiere al objeto, lo posee presentándolo. Si el término intencional se reserva para caracterizar el objeto, entonces se captará con más precisión la índole del objeto y del acto.

Dicho esto, ¿qué significa que el objeto sea intencional? Polo dedica al tema bastantes páginas, en las que considera que debe demorarse con dos ejemplos, (comparando al objeto con la fotografía y distinguiéndolo del reflejo en el espejo) pues en abstracto resulta difícil ${ }^{42}$. Resumidamente, intencional quiere decir que el objeto "está por" la realidad pero sin sustituirla, consistiendo totalmente en referir a ella. El objeto no es copia de la realidad, porque entonces sería autoconsistente y por tanto se guardaría inevitablemente referencia a sí mismo. Pero es un puro referir, su índole es la referencialidad pura. Por ello, no se puede decir que el objeto sea, que tenga consistencia ontológica. De hecho, en estrictos términos polianos, el objeto no "es", sino que "lo hay", porque en caso de ser tendría que ser real, y eso complicaría su pape ${ }^{43}$. Recapitulando un poco, se verá que esta tesis acerca de la intencionalidad es consecuencia de

[40] Curso, Tomo I, p. 41.

[41] Conmensuración no quiere decir aquí identidad, sino lo siguiente: ninguno sobra respecto del otro, no hay más pensar que el pensar lo pensado y no hay más pensado que el que hay en el pensarlo. Dicho de otro modo: ¿para qué quiero un "trozo" de pensar que no piensa nada? (sería un pensar ciego); o ¿cómo puedo hablar de un "trozo" de lo pensado que en realidad es lo nopensado porque queda fuera de lo pensado? Por otro lado, hablar aquí de identidad sería ofrecer una solución ficticia, pues implicaría decir que lo pensado y el pensarlo son lo mismo, pero es patente a la experiencia que no es así.

[42] Curso, Tomo I, p. 95-138.

[43] Además, en caso de "ser", debería su existencia a un acto de ser real extramental, pero no es así: debe su "existencia" a un acto real de conocer. En correspondencia, a dicho acto de conocer se le puede llamar también acto de haber o haber (Curso, Tomo II, p. 98).

THÉMATA. Revista de Filosofía, N50 julio-diciembre (2014) pp.: 273-293 doi: 10.12795/themata.2014.i50.13 
haberse tomado en serio hasta el final las tesis de que nuestro intelecto conoce "intra se considerando, non extra se inspiciendo" y que "para las cosas, ser conocidas es una denominación extrínseca".

Así se puede decir que entiende Polo, a grandes rasgos, la dualidad acto-objeto como estructura medular del conocimiento.

\section{Comparación}

Se captan sencillamente las evidentes diferencias entre ambos autores a tenor de lo expuesto aquí. Teniendo en cuenta el límite de espacio de este trabajo, me limitaré a compararlos en dos aspectos: la intencionalidad, y que ambos notan que esta estructura intelectiva tiene un límite. Ambos aspectos los procuraré tratar breve e incoativamente. Lo dicho a partir de aquí abandona el plano hermenéutico y pasa al de la opinión.

\subsection{Intencionalidad e inmanencia}

A las diferencias, ya expuestas, sobre este tema entre ambos autores, quiero sumar la comparación en un aspecto complementario a la intencionalidad: la noción de inmanencia.

Ambos autores hablan de inmanencia a la hora de caracterizar la relación del acto a su objeto. En el caso de Scheler, sólo en la intuición fenomenológica, pues ésta es su diferencia respecto de la concepción natural del mundo y la científica (en última instancia, el simbolismo en Scheler es un modo de falta de inmanencia). Scheler entiende la inmanencia como la inmediatez en el ser dado del objeto, en dos sentidos:

1. en cuanto el objeto y sólo el objeto es lo dado (no algo más que él),

2. en cuanto es dado sin mediación simbólica.

Aquí Scheler está hablando de inmanencia en el sentido fuerte, de conmensuración ${ }^{44}$ entre el acto y el objeto: no hay más acto que objeto ni viceversa, y no hay pseudo-objeto simbólico de por medio. Ahora bien, puesto que el acto es intencional, hay, ya hemos dicho, una cierta distancia entre el acto y el objeto, que la intencionalidad del acto se encarga de recorrer (así puede decir que el objeto de esta intuición es la cosa real en su misma esencia).

Polo, en contraste (o quizás en continuidad) con Scheler, entiende la inmanencia de modo más radical, abarcando la dimensión temporal y ontológica. Puesto que considera intencional al objeto, la operación lo posee en estricta simultaneidad, en posesión simultánea (una vez caracterizada la

[44] El término es de Polo, en Scheler no lo he encontrado, pero me parece ilustrativo.

THÉMATA. Revista de Filosofía, Nº50 julio-diciembre (2014) pp.: 273-293 doi: 10.12795/themata.2014.i50.13 
operación como praxis téleia, como genuino acto en sentido aristotélico). Esta simultaneidad permite que el objeto sea siempre intencional, es decir, que no quepa un objeto puro ${ }^{45}$.

\subsection{El límite}

Ambos autores notan que esta estructura no es omniabarcante, es decir, que tiene un límite. Este límite no es imputable, es decir, no es una deficiencia que haga a dicha estructura al cabo errónea y prescindible. El límite lo captan en dos dimensiones distintas, por decirlo así: estructural y temáticamente.

El límite estructural consiste en lo siguiente: dado que acto y objeto son indisociables, el propio acto nunca puede ser objeto. Si un extremo de la estructura se vertiese en el otro, cobraría automáticamente la índole del otro, y por tanto perdería la suya propia. Es una imposibilidad fáctica, no lógica. Scheler lo dice así:

"Los actos mismos no pueden seguramente convertirse en objetos nunca ni en modo alguno, pues su ser consiste exclusivamente en la ejecución" ${ }^{46}$.

"Ningún acto es comprobable mediante un acto de su misma clase" ${ }^{47}$.

Polo, por su parte, lo dice del siguiente modo:

"El problema se resuelve si se admite una reflexión sobre el pensar, pero no una cualquiera, sino una reflexión tal que permitiera poseer el cogito como acto. Pero esto es imposible porque poseer el objeto no es poseer el acto. La operación inmanente no es autoposesiva y por eso no es simétrica. Cabe decir que es poseída por el sujeto, pero no cabe decir que dicha posesión es una operación"48.

"En suma, la reflexión es otra operación, la cual no es reflexiva respecto de sí. Si fundimos operación y reflexión, perdemos de vista los actos cognoscitivos superiores a las operaciones. (...) De acuerdo con el axioma A, la operación visual posee objeto, pero no se posee a sí misma, no es reflexiva, a no ser que por reflexión se entienda su refluencia en la facultad" 49 .

[45] Una breve referencia a Millán-Puelles valdrá quizás para aclarar esta cuestión. Para MillánPuelles el objeto puro es aquel que es irreal, es decir, cuyo ser se agota en ser dado a una conciencia (cfr. Teoría del objeto puro, Madrid, Rialp 1990, p. 164). Para Polo esto no es así, sino que, como hemos explicado, el ser del objeto se agota en remitir intencionalmente; aunque sí es cierto que no consiste ontológicamente al modo de la realidad extramental (es decir, no es), y por eso Polo dice que "lo hay".

[46] Der Formalismus, GW 2, p. 90, cfr. p. 374, 386; Die Idole der Selbserkenntnis, GW 3, 233-4.

[47] Lehre von der drei Tatsachen, GW 10, p. 445.

[48] Curso, Tomo I, p. 84.

[49] Curso, Tomo I, p. 226-7.

THÉMATA. Revista de Filosofía, Nº50 julio-diciembre (2014) pp.: 273-293 doi: 10.12795/themata.2014.i50.13 
En ambos autores queda clara la imposibilidad de una estricta reflexividad, de que el acto se conozca a sí mismo por sí mismo o en su propio objeto. De modo que, en principio, el acto no se puede conocer (ni en general ni in actu exercitu) salvo que se descubra un nuevo método de conocimiento distinto del acto-objeto. Tal descubrimiento es necesario, pues si hablamos de acto, como llevamos haciendo todo este trabajo, quiere decir que al menos un poco lo conocemos.

Las soluciones que proponen ambos autores difieren entre sí. Scheler propone lo que llama el acto de reflexión (Reflexion) y Polo los hábitos intelectuales adquiridos. Se entiende que, aunque Scheler llame reflexión al acto en cuestión, no por ello incurre en reflexividad, pues la reflexividad sería si fuese el mismo acto el que se conoce. Ambos autores coinciden en que se trata de otro acto (en el caso de Polo acto no operativo) que no objetiva el acto. Veamos primero la propuesta de Scheler:

"A la esencia de los actos pertenece el ser vividos únicamente en la realización y el ser dados en la reflexión (Reflexion). Por consiguiente, nunca puede convertirse un acto, a su vez, en objeto merced a un segundo y acaso retrospectivo (rückblickenden) acto. Tampoco es "objeto" en la reflexión que hace consciente al acto superando su realización ingenua: el saber reflejo "acompaña" (begleitet) al acto, pero no lo objetiva"50.

“Esta «reflexión» no es «objetivación» ni «percepción», por tanto tampoco «percepción interna", la cual sólo es una clase especial de acto. La reflexión es sólo un acompañar (Mitschweben) la "conciencia de», completamente carente de cualificación, al acto que se ejecuta (...). El hecho de la reflexión es diferente de cualquier actitud representativa en general. También un acto de percepción externa puede estar dado de este modo en la reflexión al ser ejecutado" 51

La noción clave, como se habrá notado, es la de acompañar. En el caso de Mitschweben la traducción literal sería co-flotar o co-planear, que es todavía más expresivo. El resto de nociones son repeticiones directas o indirectas de lo ya dicho anteriormente; pero ésta supone un nuevo paso adelante. Si no cabe un segundo momento activo (que sería una manera sutilmente torpe de objetivar el acto) para conocer el acto, hay que encontrar una alternativa. Scheler la encuentra en la clásica noción de acompañamiento o concomitancia: sólo un acto que acompaña a otro acto puede no ser objetivante, sino tematizar de otra manera su tema. Esta manera no es descrita concretamente por Scheler (salvo con la imprecisa y polivalente noción de intuición ${ }^{52}$ ), y por lo tanto se debe precisar un poco. Lo intentaremos, intentando a su vez no violar el pensamiento scheleriano. Si un acto acompaña a otro, queda en la sombra, se oculta tras

[50] Der Formalismus, GW 2, p. 374.

[51] Die Idole der Selbserkenntnis, GW 3, 234.

[52] "Ser traídos a la intuición reflexiva en la realización de actos de diverso tipo" Der Formalismus, GW 2, p. 90.

THÉMATA. Revista de Filosofía, №50 julio-diciembre (2014) pp.: 273-293 doi: 10.12795/themata.2014.i50.13 
del acto acompañado que ostenta por tanto la primacía; de otro modo no sería acompañante sino principal. Estaríamos frente a un "declarar ocultándose"53.

Si ponemos atención, estamos acercándonos peligrosamente al método de la intuición fenomenológica. A nuestro juicio no podía ser de otro modo, y en este punto nos permitimos una valoración de la postura scheleriana. Al acercarse a la intuición fenomenológica, convertiría, como es evidente, al acto en un objeto (aunque objeto de la más alta dignidad, qué duda cabe). Scheler, al sentar como lo hace la intencionalidad y la inobjetivabilidad del acto, se ha cortado las manos. Si el acto es intencional, se diluye en su objeto, se asimila al deseo de acto más que al acto efectivo ${ }^{54}$, y así pierde fuerza. No obstante, esta asimilación no es total porque Scheler tiene la agudeza de eximir al acto de cualquier duración temporal ${ }^{55}$ : por decirlo así, es una asimilación ontológica.

Con motivo de esta su índole, el acto solicita a gritos su aclaración, la declaración de que existe y opera, pues su valor cognoscente queda puesto en entredicho: en lugar de estar ante un "conocer que conoce lo conocido" estamos ante un "conocido que se hace patente solicitando para ello un escenario mínimamente adecuado". Si además el acto es inobjetivable por esencia, estamos pudiendo definirlo sólo por su oposición con el objeto, el cual toma por tanto la primacía ontológica. Por tanto, de modo paradójico, Scheler ha objetivado el acto, al haberlo entendido como simétricamente opuesto al objeto. Dicho de otro modo: si tenemos un objeto, y un $\mathrm{X}$ que consiste en no ser objeto, en realidad tenemos dos objetos, dos contenidos con notas definitorias. Es, llamémosla así, la paradoja del eterno segundón, del que siempre se compara, del que se reduce a sí mismo a la comparación con otro ${ }^{56}$. Aún más ocurre esta sutil objetivación si la distinción entre acto y objeto en Scheler es metafísicamente hegemónica. La palabra clave aquí es simetría. Para tomar en toda su profundidad que el acto es inobjetivable, hay que romper las categorías schelerianas. A

Esta objetivación de los actos sale a relucir en el conocimiento de ellos que Scheler propone. Aunque ya hemos visto que no expone el método de la Reflexion, sí que expone qué es lo que conoce del acto: su identificabilidad. Los

[53] El término tiene residuo heideggeriano, y se emplea únicamente por su expresividad.

[54] Cfr. Haya, F.; op. cit, p. 38. La opinión de Haya (op. cit, p. 75), es que Scheler supera el constructivismo gnoseológico. Aquí no creemos que sea así exactamente: la orecticidad lleva a Scheler al constructivismo, porque si al acto le falta una distancia por cubrir hasta su objeto, el conocimiento está aún por ocurrir, por construirse. Claro que es un constructivismo moderado, porque no es del objeto sino del acto.

[55] Cfr. Die Idole der Selbserkenntnis, GW 3, 234.

[56] En este punto me permito dos breves reflexiones muy opinables. No deberían sonar extrañas llegados a este problema, dos cosas: que desde su perspectiva Kant se negara a hablar de actos (en plural) de la inteligencia y los redujese todos al "yo pienso", y que el tercer Scheler (de 1922 hasta 1928) negase toda actividad del lado del acto y la atribuyese a la naturaleza y a los apetitos (cfr. Die Stellung des Menschen im Kosmos, GW 9, pp. 7-72)

THÉMATA. Revista de Filosofía, Nº50 julio-diciembre (2014) pp.: 273-293 doi: 10.12795/themata.2014.i50.13 
actos pueden ser identificados, es decir, se pueden intuir sus esencias diferenciales (differentielle Wesenheiten), las cuales consisten solamente en qué tipo de objeto traen consigo ${ }^{57}$. Como ya hemos visto, aquí Scheler cree (a nuestro juicio erróneamente) que identificar los objetos en virtud de los actos implica necesariamente caer en lo que llama el trascendentalismo kantiano. Bien es cierto también que sería difícil que creyera otra cosa, entendiendo como entiende los conceptos de material y a priori.

La noción de Reflexion no es la única manera que propone Scheler para conocer el acto, pero sí es la más lograda epistemológicamente. La otra alternativa sería el vivir (Erleben) dichos actos ${ }^{58}$. Este método tiene el claro inconveniente de que en realidad es una invitación psicológica ("viviendo los actos te darás cuenta de lo que son”), pero no es ninguna propuesta gnoseológica, porque no habla del método por el que nos son dados. Es como desviar la pregunta, como si decimos "dime con quién andas y te diré quien eres", pero no podemos decir cómo se conoce el sujeto. No es que sea falso, es que se queda en el umbral psicológico de la cuestión. En el fondo es lo mismo que decir: "no sé como se conocen, pero los conozco". Al no entrar en terreno gnoseológico y no complicarse con el objetivismo, tiene la ventaja de respetar la índole estrictamente activa de los actos, al decir que sólo pueden ser conocidos en primera persona in actu exercitu. Con este método, por tanto, Scheler no habría objetivado el acto por simetría, pero en virtud de la sutil trampa de no haberlo tematizado. En favor de esto cabría argüir que Scheler impide a la filosofía la tematización del acto cuando dice que los límites de la objetividad son los límites a priori del conocimiento ${ }^{59}$, pero no creemos justo tomar tan radicalmente una afirmación que bien puede pasar por esporádica.

Por su parte, Polo propone algo ligeramente distinto para conocer el acto. Se podría decir que fenomenológicamente la solución es parecida, pues ambos detectan que en el mismo ejercicio de la operación co-actúa un conocer no-operativo que es consectario o concomitante con el primero y que lo declara sin objetivarlo. Pero la caracterización gnoseológica (y ontológica) de dicho conocer consectario es bien diferente en Polo y en Scheler.

Ante todo, para hacer justicia al pensamiento de Polo, hay que decir que la necesidad de conocer el acto le parece un planteamiento erróneo de la cuestión: "la noción de auto-aclaración es la postergación de la aclaración respecto del acto: el acto tiene que ser aclarado. Y si tiene que ser aclarado, de antemano

[57] Cfr. Der Formalismus, GW 2, p. 375. En este punto, nos adherimos al breve y contundente análisis de Santamaría, M.G.; op. cit, pp. 36-39, el cual termina concluye así: "en definitiva, no podemos resolver en unidad la radical disociación scheleriana entre objetividad cognoscitiva esencializante y actualidad" (p. 41). De todos modos no nos satisface la aceptación, parcial, por parte de Santamaría de la intencionalidad del acto.

[58] Cfr. Der Formalismus, GW 2, p. 386.

[59] Cfr. Vom Wesen der Philosophie, GW 5, p. 71.

THÉMATA. Revista de Filosofía, №50 julio-diciembre (2014) pp.: 273-293

doi: 10.12795/themata.2014.i50.13 
no lo estaba, por lo que el cometido del conocimiento es remediar la ceguera de su propio acontecer: colmar su propia ignorancia a priori. La interpretación del conocimiento como acontecer dirigido a colmar su propia ignorancia (una ignorancia a priori) es lo peculiar del planteamiento moderno. La historia de la filosofía moderna es, en buena parte, la historia de las postergaciones del objeto"60. Esto no quiere decir que no haya que tratar el tema que estamos tratando, sino que hay que tratarlo cambiando ligeramente el punto de partida: no hay que pensar en una operación ejercida que necesita ser aclarada, sino una operación en ejercicio en concomitancia con su propia declaración (el término aclaración está viciado, como es patente).

El modo de declaración o conocimiento de las operaciones es, como ya hemos dicho, los hábitos. Los hábitos según Polo son un modo de conocer de índole estrictamente distinta de las operaciones, y por ello pueden acompañarlas.

"Lo que se pretende explicar con la noción de reflexión -que, por otra parte, es una experiencia conocer que se conoce- es realmente la iluminación de la operación por el hábito”61.

"Si se rechaza la noción de reflexión, entonces tenemos que rectificar la relación entre hábito y operación, y decir que el hábito es el conocimiento de la operación, y a ese conocimiento lo llamo manifestación" 62 .

"Los hábitos son otro tipo de acto" ${ }^{63}$.

Como habíamos dicho arriba, la operación es humilde, es decir, se oculta: se limita a presentar, es puro presentar lo presentado y no a sí misma. Este ocultamiento es desvelado concomitante e inmediatamente por el hábito que la acompaña.

Estas ideas son tres pinceladas básicas sobre una noción muy amplia y relevante ("la noción de hábito es la más importante de la teoría del conocimiento humano"64). Su explicación está desperdigada por todo el corpus poliano, y además no está suficientemente precisada. Polo se preocupa de comparar su postura con el tratamiento medieval de los hábitos, el cual a su juicio los asimila demasiado a los hábitos de la voluntad. Esta es la clave para asomarse a la noción poliana de hábito intelectual, distinguirlo del hábito moral o virtud; y esto significa 4 tesis $^{65}$ : los hábitos intelectuales no se adquieren con esfuerzo,

[60] Curso, Tomo II, pp. 173-4. La idea de identificar la modernidad con la postergación está tratada, en sede antropológica, en "El radical moderno", en Persona y libertad, Eunsa, Pamplona 2007, pp. 183-205.

[61] Curso, Tomo IV/2, 1996, 157.

[62] El logos predicamental, Cuadernos de Anuario Filosófico, Serie Universitaria, Servicio de Publicaciones de la Universidad de Navarra, Pamplona, 2006, p. 107.

[63] Curso, Tomo I, p. 39.

[64] Curso, Tomo I, p. 220.

[65] Cfr. Sellés, J. F.; "Los hábitos intelectuales según Polo”, en Anuario Filosófico, 29 (1996), pp. 1017-1036.

THÉMATA. Revista de Filosofía, Nº50 julio-diciembre (2014) pp.: 273-293 doi: 10.12795/themata.2014.i50.13 
no son incrementables, cada operación tiene el suyo propio y son superiores a las operaciones porque son más activos. No vamos a entrar en ellas, sólo diremos que desde Polo no se puede definir qué sea un hábito intelectual, al menos por dos razones. La primera, porque al ser transobjetivos son a su vez indefinibles. La segunda, porque Polo dedica los textos en los que habla de los hábitos a mostrar su rendimiento más bien que su índole ${ }^{66}$.

El límite temático es dependiente del límite estructural, y ambos autores lo notan del siguiente modo: hay temas que no caben en esa estructura, que desbordan el objeto. En el fondo ocurre porque dichos temas son, dicho rápidamente, acto o más que acto. En el caso de Scheler es la persona como espíritu que vive en sus actos, en el caso de Polo son 4 temas: la esencia de la persona humana (la humanidad de cada quién, la propia elaboración de la dotación human nativa, que son las potencias espirituales), la persona human misma (el cada quien, la libertad personal), la esencia del universo y el acto de ser del universo. Proponer los métodos ensayados por cada autor para esto excedería el propósito de este trabajo.

[66] Así hace Polo en las siguientes obras: Curso, Tomo IV/b, El conocimiento habitual de los primeros principios, Cuadernos de Anuario Filosófico, Serie Universitaria, Servicio de Publicaciones de la Universidad de Navarra, Pamplona, 1993, El conocimiento racional de la realidad, Cuadernos de Anuario Filosófico, Serie Universitaria, Servicio de Publicaciones de la Universidad de Navarra, Pamplona 2004, Antropología trascendental, Tomo I.

THÉMATA. Revista de Filosofía, №50 julio-diciembre (2014) pp.: 273-293

doi: 10.12795/themata.2014.i50.13 
